\title{
Thrombotic thrombocytopenic purpura mimicking acute small bowel Crohn's disease
}

\author{
P J Winwood, J P Iredale, P J Williamson, M Lesna, C A Loehry
}

\begin{abstract}
A 39 year old woman presented with a short history of bloody diarrhoea. She subsequently developed microangiopathic haemolysis, platelet consumption, and renal impairment. Initial investigations suggested underlying Crohn's disease of the terminal ileum complicated by sepsis and disseminated intravascular coagulation. However, after resection of a perforated caecum and terminal ileum, the diagnosis of thrombotic thrombocytopenic purpura was made. There was weak serological evidence of yersinia infection, this may have caused the early localisation of the lesions to the terminal ileum. This is believed to be the first report of thrombotic thrombocytopenic purpura affecting the small bowel alone at presentation.
\end{abstract}

Departments of Medicine and Pathology,

Bournemouth General

Hospital, Bournemouth

P J Winwood

J P Iredale

M Lesna

C A Loehry

Department of

Haematology,

Southampton General

Hospital, Southampton

P J Williamson

Correspondence to:

Dr P Winwood, Medicine II

Level D, South Lab and Path

Block, Southampton General

Hospital, Tremona Road,

Southampton.

Accepted for publication

7 October 1991

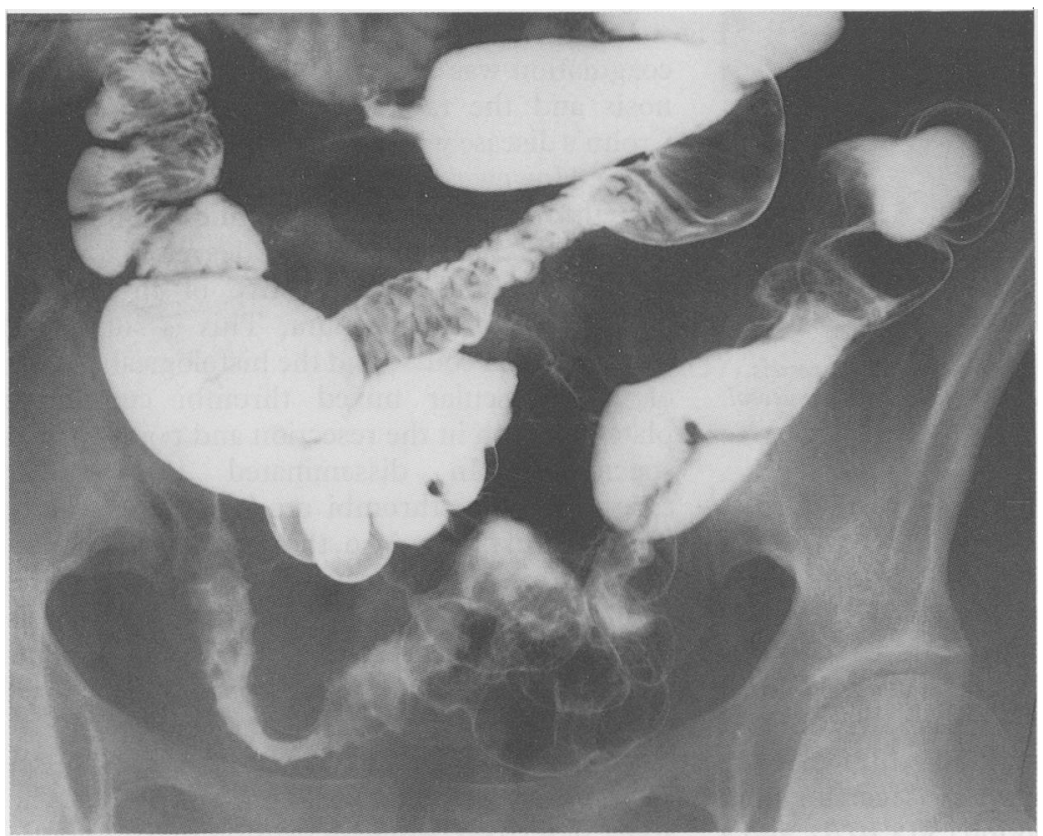

Figure 1: Small bowel barium meal showing oedema of the terminal ileum. infective or inflammatory colitis following one week of bloody diarrhoea, colicky abdominal pain, vomiting, and fever. There was no other history of note and she was not taking oral contraceptives or any other medication. Initial investigations showed a leukocytosis $(27 \cdot 3 \times$ $\left.10^{9} / 1\right)$, a normal haemoglobin concentration $(14 \cdot 7 \mathrm{~g} / \mathrm{dl})$ and platelet count $\left(262 \times 10^{9} / \mathrm{l}\right)$, and hypoalbuminaemia $(31 \mathrm{~g} / \mathrm{l})$. Other investigations including stool cultures were normal. She was rehydrated intravenously and, because of her toxic state, intravenous cefuroxime, metronidazole, hydrocortisone (100 $\mathrm{mg}$ four times daily) were begun.

Four days later the fever and diarrhoea continued and she became uncharacteristically agitated. Her urine output fell to $400 \mathrm{ml}$ per 24 hours despite adequate rehydration, and there were increases in plasma urea $(19.7 \mathrm{mmol} / \mathrm{l})$ and creatinine $(220 \mu \mathrm{mol} / \mathrm{l})$. This was associated with microscopic haematuria, a fall in haemoglobin $(8.3 \mathrm{~g} / \mathrm{dl})$ and platelet count $\left(39 \times 10^{9} / \mathrm{l}\right)$, and an increasing leukocytosis $\left(45 \times 10^{9} / 1\right)$. The blood film showed crenated red cells, burr cells, schistocytes, and nucleated red cells. Concomitantly, there was prolongation of the prothrombin time $(20.2$ seconds, control 15.5$)$ and thrombin time (21.5 seconds, control 13.7) and the titre of D-dimer fragments of fibrin (XDPs) was raised (500-1000 $\mathrm{ng} / \mathrm{ml}$ ). A picture consistent with microangiopathic haemolysis and disseminated intravascular coagulation. Marrow aspirate and trephine showed plentiful normal megakaryocytes and reactive features. Abdominal radiographs showed dilated small bowel loops and multiple fluid levels on an erect film. After a change in antibiotic therapy and the administration of fresh frozen plasma there was a dramatic clinical improvement with a return of renal function and the blood count to normal. The blood, film, however, continued to show fragmented red cells.

A small bowel meal showed an oedematous stricture of the terminal ileum strongly suggestive of Crohn's disease (Fig 1). No other source of sepsis was detected by abdominal ultrasound or computed tomography.

On day 22 after hospital admission she was well, taking a reducing course of oral prednisolone only, and ready for discharge. However, 24 hours later she became acutely ill with clinical features of intestinal perforation and thrombocytopenia $\left(89 \times 10^{9}\right)$. At laparotomy the terminal ileum and caecum were inflamed with multiple perforations necessitating hemicolectomy and resection of the terminal ileum.

Histology of sections from the resected bowel showed mucosal ulceration with occlusion of submucosal arterioles by recent and organising thrombi (Fig 2). There was no vasculitis or 

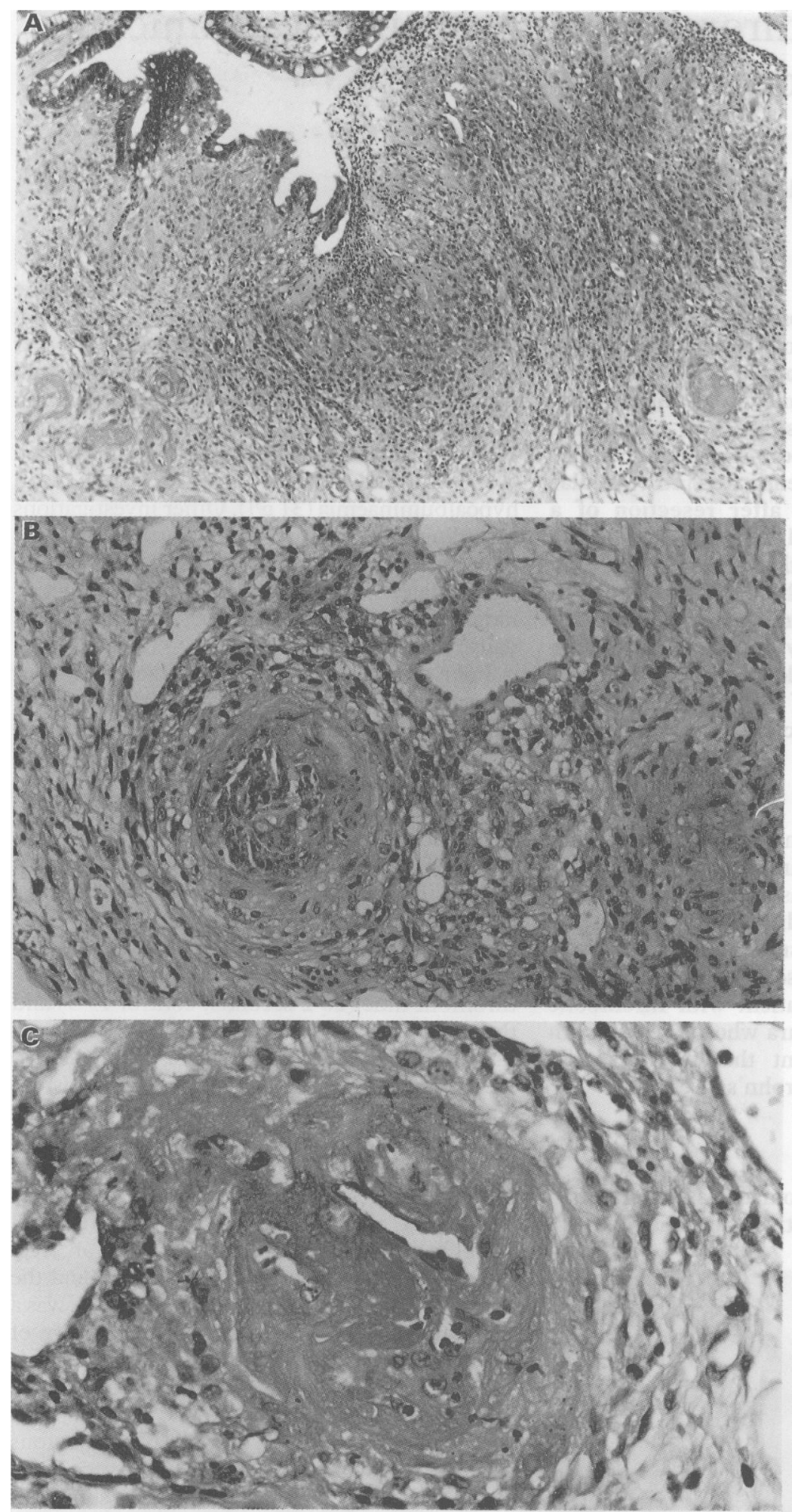

Figure 2: (A) Ischaemic ulceration of the caecum with thrombosed submucosal blood vessels. (Haematoxylin and eosin, original magnification $\times 75$.) $(B)$ Mixed thrombus in a submucosal artery of the terminal ileum. (Haematoxyline and eosin, original magnification $\times 300$.) (C) Organised thrombus in a submucosal arteriole of the caecum. (Haematoxylin and eosin, original magnification $\times 600$.) coagulation disturbance, slightly raised XDPs and raised bilirubin $(41 \mu \mathrm{mol} / \mathrm{l})$. A diagnosis of thrombotic thrombocytopenic purpura was made and treatment with daily plasmapheresis was begun ( 31 exchanges with 21 of fresh frozen plasma and 11 of normal saline) in addition to intravenous steroids and antibiotics. As there was no clinical improvement after one week, despite a partial recovery in platelet count, she was also given two doses of vincristine $(2 \mathrm{mg}$ ) one week apart. On day 21 after operation she developed respiratory distress syndrome that required ventilation. Despite intensive treatment, cerebral oedema and renal failure ensued. She died four weeks after surgery.

At necropsy, apart from the complicating respiratory distress syndrome, there were further multiple discrete ischaemic areas in the small and large bowel, enlarged pale kidneys with identical microangiopathy, and cerebral oedema. None of the thrombi were of the type seen in disseminated intravascular coagulation (see Discussion); some were fresh while others were in different stages of organisation. On retrospective assessment, the changes were most severe in the resected ileum and caecum. Serology from one week after admission showed raised Yersinia enterocolitica $0: 9$ antibody titres of $1: 320$, consistent with recent infection (result received after the patient's death).

\section{Discussion}

Thrombotic thrombocytopenic purpura is a rare, acute condition of undetermined aetiology. It is characterised by a pentad of features first described by Amorisi. ${ }^{+}$These consist of fever, bleeding or purpura - generally with thrombocytopenia, microangiopathic haemolytic anaemia, neurological manifestations, and renal disease, as demonstrated by this patient. Routine coagulation tests are usually normal, although a minority of cases have a mild disturbance ${ }^{45}$ which may represent disseminated intravascular coagulation secondary to red cell fragmentation. ${ }^{6}$

In this patient disseminated intravascular coagulation was our initial haematological diagnosis and the radiological findings led us to Crohn's disease with an abscess as the underlying cause. However, the disproportionate severity of the thrombocytopenia and microangiopathic haemolysis compared with the degree of coagulation disturbance is suggestive of thrombotic thrombocytopenic purpura. This is supported by the clinical course and the histological finding of microvascular mixed thrombi containing platelets, both in the resection and post mortem specimens. In disseminated intravascular coagulation the thrombi are largely or wholly composed of fibrin. Also, the initial improvement seen in this patient may have been due to the fresh frozen plasma she was given, which is effective in treating some patients with thrombotic thrombocytopenic purpura when used alone. $^{\text {? }}$

The alternative diagnosis is adult onset haemolytic uraemic syndrome in which the above described pentad of features of thrombotic thrombocytopenic purpura can be seen. The mesenteric blood vessels were normal.

After operation she became confused, drowsy, and feverish, followed by several grand mal convulsions. Her renal function deteriorated again and the blood count and film showed microangiopathic haemolysis (haemoglobin $8.0 \mathrm{~g} / \mathrm{dl})$, platelet consumption $\left(30 \times 10^{9} / \mathrm{l}\right)$, and a leukocytosis. There was an associated mild 
major differences are that early multiorgan involvement and a fulminant course are features more of thrombotic thrombocytopenic purpura than haemolytic uraemic syndrome, however the histopathological findings of affected organs are identical..$^{5}$ Indeed, there may be some overlap between the two conditions. Neurological manifestations, when seen, tend to occur late in the course of haemolytic uraemic syndrome. In this patient, although florid neurological features (drowsiness and fits) did not occur until 23 days after presentation, she was uncharacteristically agitated on day 4 . At the time steroid induced psychosis was considered a possible cause, but her agitation resolved with clinical improvement in spite of continuing high dose steroid treatment. In retrospect, this was probably early cerebral involvement by thrombotic thrombocytopenic purpura. Finally, although colitis has been described in haemolytic uraemic syndrome, ${ }^{12}$ presentation with small bowel ischaemia alone has not.

The isolation of certain bacteria and viruses in cases of thrombotic thrombocytopenic purpura has led to the suggestion that an infective aetiology may be important ${ }^{7}$ and there is evidence that exacerbations of recurrent thrombotic thrombocytopenic purpura are linked to episodes of infection..$^{89}$ Moreover, in haemolytic uraemic syndrome there are strong links with gastrointestinal infections such as verocytotoxin producing $E$ coli $^{10}$ and shigella ${ }^{11}$ Therefore, yersinia infection may have precipitated thrombotic thrombocytopenic purpura and linked the pathological process to the terminal ileum in this case. Against this, the histology of resected ileum showed microvascular occlusive disease identical to that in the post mortem kidneys, typical of thrombotic thrombocytopenic purpura, and with no specific features to suggest recent infection. The normal platelet count at presentation might favour the initial diagnosis of yersinia infection, but this is recognised in thrombotic thrombocytopenic purpura. ${ }^{+}$

Evidence of gastrointestinal involvement in thrombotic thrombocytopenic purpura, as in the haemolytic-uraemic syndrome, is surprisingly common; up to $30 \%$ of patients having abdominal pain at presentation. ${ }^{5}$ This abdominal pain has been ascribed to pancreatitis secondary to occlu- sion of pancreatic arterioles. ${ }^{12}$ However, vascular occlusion of the colonic wall ${ }^{13}$ and massive gastro-oesophageal haemorrhage ${ }^{14}$ have also been reported.

We are not aware of any previous reports of bloody diarrhoea in association with abdominal pain occurring at the onset of thrombotic thrombocytopenic purpura and before any of the other clinical or laboratory features become manifest. Similarly, we have found no reports of thrombotic thrombocytopenic purpura or haemolytic uraemic syndrome presenting with discrete infarction of the terminal ileum and caecum clinically and radiologically indistinguishable from Crohn's disease. It is a reminder of the differential diagnosis of Crohn's disease of the terminal ileum.

1 Craner GE, Burdock GE. Acute colitis resembling ulcerative colitis in the hemolytic-uremic syndrome. Dig Dis 1976; 21: 74-6.

2 Berman W Jr. The hemolytic-uremic syndrome: initial clinica presentation mimicking ulcerative colitis. $\mathcal{f}$ Pediatr 1972 81: $275-8$.

3 Williamson LM, Johnstone JM, Preston FE. Micro-vascular thrombosis of the bowel in paroxysmal nocturnal haemoglobulinaemia. $\mathcal{f}$ Clin Pathol 1987; 40: 930-1.

4 Amorosi EL, Ultmann TE. Thrombotic thrombocytopenic purpura: report of the 16 cases and review of the literature. purpura: report of the 16 cases and re
Medicine (Baltimore) 1966; 45: 139-59.

5 Byrnes JJ. Thrombotic thrombocytopenic purpura. Adv Intern Med 1986; 26: 131-57.

6 Jaffe EA, Nachman RL, Merskey C. Thrombotic thrombocytopenic purpura: coagulation parameters in twelve patients. Blood 1973; 42: 499-507.

7 Byrnes JJ, Moake JL. Thrombotic thrombocytopenic purpura and the Haemolytic-Uraemic Syndrome: evolving concepts of pathogenesis and therapy. Clin Haematol 1986; 15 413-42.

8 Boswell DC, Sierra G. Probable 16-year course in a patien with thrombotic thrombocytopenic purpura. Illinois Medical fournal 1974; 145: 29-31.

9 Upshaw JD. Congenital deficiency of a factor in normal plasm that reverses microangiopathic haemolytic anaemia. $N$ Engl that reverses microangiop

10 Milford DV, Taylor CM, Guttridge B, Hall SM, Rave B, Kleanthous $H$. Haemolytic uraemic syndromes in the British Isles 1985-8: association with verocytotoxin producing Escherichia coli. Part I: clinical and epidemiological aspects. Arch Dis Child 1990; 65: 716-21.

11 Karmali MA, Petric M, Linn E, et al. The association between idiopathic haemolytic uraemic syndrome and infection by verocytotoxin-producing E. Coli. F Infect Dis 1985; 151: 775-82.

12 Harrison KN. Thrombotic thrombocytopenic purpura occurring in the puerperium: associated with pancreatic islet-cell ring in the puerperium: associated with pancie

13 Civin H, Gotshalk HC. 'Platelet thromboses' involving the gastrointestinal tract: report of a case. Hawaii Med $\mathcal{F} 1953$; 13: 119-21.

14 Hellstrom HR, Nash EC, Fischer ER. Thrombotic thrombocytopenic purpura as a cause of massive gastrointestina haemorrhage: report of a case. Gastroenterology 1959; 36 $132-6$. 